\title{
The income-associated burden of disease in the United States
}

\author{
Peter Muennig ${ }^{\mathrm{a}, *}$, Peter Franks ${ }^{\mathrm{b}}$, Haomiao Jia ${ }^{\mathrm{c}}$, Erica Lubetkin ${ }^{\mathrm{d}}$, Marthe R Gold ${ }^{\mathrm{d}}$ \\ ${ }^{a}$ Department of Health Policy and Management, Mailman School of Public Health, Columbia University, $600 \mathrm{~W} 168 \mathrm{th}$ St., 6th Floor, \\ New York, NY 10032, US \\ ${ }^{\mathrm{b}}$ Center for Health Services Research in Primary Care, Department of Family \& Community Medicine, \\ University of California, Davis, US \\ ${ }^{\mathrm{c}}$ Department of Community Medicine, Mercer University School of Medicine, Macon, GA, US \\ ${ }^{\mathrm{d}}$ Community Health and Social Medicine, The City University of New York Medical School, New York, NY, US
}

Available online 23 May 2005

\begin{abstract}
In this study, we estimate the total burden of disease associated with income in the US. We calculate the relationships between income and life expectancy, health-adjusted life expectancy, annual years of life lost (YLLs), and health adjusted life years (HALYs). We used the 2000 US Medical Expenditure Panel Survey to derive quality of life estimates by income and age, the 1990-1992 US National Health Interview Survey linked to National Death Index data through the end of 1995 to derive mortality risks by income and by age, and 2000 US mortality data from the National Center for Health Statistics to derive current mortality estimates for the US population by age-group. The bottom $80 \%$ of adult income earners' life expectancy is 4.3 years and 5.8 HALYs shorter relative to those in the top $20 \%$ of earnings. This translates into the loss of 11 million YLLs and 17.4 million HALYs each year. Compared with persons living above the poverty threshold, those living below the poverty threshold live an average of 3.2 million fewer HALYs per year-a difference of 8.5 HALYs per individual between age 18 and death. The income-associated burden of disease appears to be a leading cause of morbidity and mortality in the US.
\end{abstract}

(C) 2005 Elsevier Ltd. All rights reserved.

Keywords: US; Health inequalities; Poverty; Burden of disease analysis

\section{Introduction}

The risk factors underlying the leading causes of death have been referred to as the "actual causes" of death (McGinnis \& Foege, 1993; Mokdad, Marks, Stroup, \& Gerberding, 2004). However, these causes, which include tobacco use, poor diet, physical inactivity, infectious disease exposure, and motor vehicle accidents are in turn influenced by another risk factor-income (Lantz et al., 1998; Smith, Shipley, \& Rose, 1990;

\footnotetext{
*Corresponding author. Tel.: + 12123057975 ; fax: +12123053405 .

E-mail address: pm124@columbia.edu (P. Muennig).
}

Stevenson, 1923). The cumulative effect of incomerelated exposures may be large; the top $5 \%$ of income earners live about $25 \%$ longer than the bottom $5 \%$ (Rogot, 1992).

While many studies have examined the relationships between income and adverse health effects, none have attempted to examine the total burden of disease associated with lower levels of income. Burden of disease studies enable comparisons using a common metric of health of the relative effects of different healthrelated problems on society. The common metric incorporating both morbidity and mortality into a single measure is the health-adjusted life year (HALY), which is a year of perfect health. Thus, burden of disease 
studies have been used both in the US and elsewhere as a policy tool to assist with description and prioritization of health risks and interventions with which to treat them (Gold, Siegel, Russell, \& Weinstein, 1996; Michaud, Murray, \& Bloom, 2001).

Income-related health effects span the range of earnings in a curvilinear dose-response relationship that levels off for the top $20 \%$ of income earners (Smith et al., 1990; Wolfson, Rowe, Gentleman, \& Tomiak, 1993). To capture the full burden of disease, we thus compare persons relatively unaffected by the income gradient (the top $20 \%$ or so) with the remainder of the population. Most poverty reduction interventions have been targeted towards persons below the federal poverty threshold (Haveman, 1995; Smeeding, Ross, \& O’Connor, 2000). We thus include a sub-analysis of this population in order to estimate the potential impact of poverty reduction programs. We explore the burden of disease using a traditional outcome measure (mortality), a comprehensive summary measure of population health (EQ-5D Index scores), and the combination of the two (Cohen, 2003).

\section{Methods}

\section{Overview and definitions}

Outcomes associated with a family income below the poverty threshold are referred to here as "poverty associated." For instance, poverty associated deaths are the total deaths for those at risk beyond what would be expected had their risk been equal to the reference group (i.e., those in the top $20 \%$ of income). Outcomes associated with family income less than approximately $80 \%$ of all households $(<80 \%)$ are referred to here as "income related." We examine the annual numbers of poverty-associated deaths and income related deaths, the annual number of years of life lost (YLL) to death, the annual HALYs lost, and changes in health adjusted life expectancy (HALE) for all groups under study.

The calculation of HALYs and HALE is achieved using health-related quality of life scores (HRQL), which provide an assessment of the importance people place on the morbidity associated with illness. These scores assume a value between 0 (death) and 1 (perfect health). Thus a year of life lived at an HRQL of 0.8 is equal to 0.8 HALYs, and a simplified estimation of HALE is the product of life expectancy and the mean HRQL for a particular group.

\section{Datasets}

We obtained HRQL values from the 2000 MEPS, and mortality ratios from the 1990-1992 National Health Interview Surveys linked to the National Death Index through the end of 1995 (AHRQ, 1996; Cohen, 2003; NCHS, 1993, 1995). This is the most recent source of nationally representative data that links household income to death certificate data (NCHS, 1995).

The MEPS is conducted by the Agency for Health Research and Quality (AHRQ), and is representative of the non-institutionalized population in the US. This annual survey includes detailed socio-demographic, utilization, and health status information. The household income data are recoded into discrete categories relating household income to the poverty threshold $(<100 \%, \quad 100-124 \%, \quad 125-199 \%, \quad 200-399 \%$, and $\geqslant 400 \%$ ). For instance, those with household earnings $400 \%$ of the poverty threshold or greater have over four times the earnings of those living at the federal poverty threshold.

In 2000 the MEPS included the EuroQol EQ-5D Index, a HALY compatible and preference-based instrument, for persons over age 18 (Coons, Rao, Keininger, \& Hays, 2000; Rabin \& de Charro, 2001). The EQ-5D Index, assesses 5 dimensions of health: 1) mobility, 2) self-care, 3) ability to perform usual activities, 4) pain or discomfort, and 5) anxiety or depression. Each dimension is scaled as "no problem," "some problem," or "extreme problem." EQ-5D Index scores were obtained from a representative sub-sample of 13,646 persons excluding proxy respondents. Responses to these 5 variables in the MEPS were linked US population weights for each of these health states (Cohen, 2003; Coons et al., 2000). The EQ-5D also contains a visual analog scale, however, this was not included in our HRQL calculations.

The NHIS contains socio-demographic variables similar to MEPS. The 1990-1992 NHIS data have been linked to National Death Index (NDI) data through the end of 1995, which allows mortality analyses to be conducted on subjects in the original sample (NCHS, 1995). The NHIS linked data sample 256,900 persons, 11,214 of whom died by the end of 1995 .

\section{Regression analyses}

Analyses were conducted using SAS version 8.2 (SAS Institute Inc., Cary, NC) and SUDAAN version 8.0.1 (Research Triangle Institute, Research Triangle Park, NC) a statistical package that allows adjustment for the complex sampling design used in the MEPS and NHIS. All calculations were weighted and adjusted for the multi-stage cluster design of the data to achieve population parameter estimates.

Spline regressions were used to derive smoothed agespecific EQ-5D scores for persons 18 and older. Spline regression uses a piecewise polynomial function that fits data locally. This method corrects for bias, particularly at boundary regions when independent variables are skewed or have outliers (Simonoff, 1996). We generated 
HRQL values for persons 18-24, 25-44, 45-64, 65-74, and $75+$. Intervals were chosen to maximize sample sizes for the hazards analysis, and are age-adjusted within each age interval. Age-specific values were used rather than a single age-adjusted score because globally age-adjusted values have been shown to overestimate overall mortality relative to age-specific values (Flegal, Williamson, Pamuk, \& Rosenberg, 2004). Regression was also used to extrapolate EQ-5D Index scores for persons under 18 . These age $0-17$ scores only were used in secondary analyses to provide an estimate of HALE at birth.

Cox proportional hazard survival models were used to generate the hazard ratios (HR) for the poverty associated (vs. not) and income related (vs. not) analyses using the same intervals generated for HRQL. Each analysis was adjusted for age and age squared. For life expectancy calculations, we calculated the risk of mortality for each income group under study relative to the mean age-specific mortality rates in the US. These relative comparisons allow for estimation of life expectancy for the general population rather than the non-institutionalized population and allow for estimation of year 2000 (rather than 1990-1995) life expectancy. We calculated relative risk by dividing agespecific rates for the lower income group $(<$ line or $<80 \%$ ) of household income by the higher income group in each analysis ( $\geqslant$ line or $\geqslant 80 \%$ of household income).

\section{Life expectancy}

Abridged life tables were generated for the general US population for the year 2000 using age intervals of 5 years (or less) to age 90 and over. They were populated with year 2000 mortality data obtained from the National Center for Health Statistics (Minino, Arias, KD, Murphy, \& Smith, 2002). Life tables were constructed using a hypothetical cohort of 100,000 individuals exposed to a risk of death over each age interval. For instance, if the risk of death between age 0 and 1 is 0.00693 , then 693 persons will die over this interval, leaving $100,000-693=99,307$ persons to be exposed to the risk of death in the next age interval. To calculate life expectancy at birth, the number of person years in each age interval are then summed across intervals and divided by the number of persons at the start of the first interval $(100,000)$.

In the base-case analysis, life expectancy and HALE were calculated at age 18 because EQ-5D Index scores were not available for younger persons. To provide familiar reference points for life expectancy and to provide estimates for the entire population, we also conducted a secondary analysis examining life expectancy at birth using mean population infant mortality rates (via the NCHS separation factor) to estimate deaths in the first interval (Anderson, 1999). Infant mortality was corrected for births occurring the year before the recorded deaths.

\section{HALE}

To calculate HALE, the number of person years in each interval is multiplied by the mean HRQL score for that interval. As with life expectancy calculations, these health-adjusted person years are summed over all age intervals and divided by the 100,000 persons at the start of the first interval. Further details pertaining to the general construction of our life tables have been published elsewhere (Anderson, 1999; Muennig, 2002).

Income and poverty related deaths were calculated as follows:

$\frac{\left(\left(\left(R_{x}-R_{x} \bullet P_{x}+P_{x}-1\right) \bullet P_{x}\right) /\left(R_{x} \bullet P_{x}+P_{x}\right) \bullet D\right)}{1-P_{x}}$,

where $R$ is the hazard ratio for at risk persons relative to the reference group at age $x, P$ is the proportion of persons in the at risk group at age $x$, and $D$ is the national number of deaths in 2000 . Total deaths were obtained from death certificate data (Minino et al., 2002). In 2000, there were $2,352,074$ deaths, of which $0.01 \%$ were excluded because no information on subjects' age was available.

\section{$Y L L$ and $H A L Y S$}

Total YLLs were calculated as

$\sum_{x=1}^{5} D_{x} \bullet L_{x}$

where $x$ is the age interval, $D_{X}$ is the number of poverty associated or income related deaths within age interval $x$ and $L_{X}$ is the life expectancy for persons above the two lines at the mid-point of age interval $x . L_{X}$ was obtained from life table values for the reference group (e.g., for the $<$ line group, life expectancy at age $x$ was used from the $\geqslant$ line group) to reflect the full potential life lost.

The total HALYs are equal to the difference in HRQL between the groups under study plus the HRQLadjusted years of future life lost when a premature death occurs. Total HALYs were calculated as

$\sum_{1}^{x}\left(\left(H_{\mathrm{A} x}-H_{\mathrm{B} x}\right) \bullet P_{x}+Y_{x} \bullet H_{\mathrm{B} x}\right)$,

where, $H_{\mathrm{A} x}$ is the HRQL score for persons above either of the two cut-off points ( $\geqslant$ line or $\geqslant 80 \%$ household income) in age interval $x, H_{\mathrm{B} x}$ is the HRQL score for persons below either of the two income thresholds in age interval $x, P_{\mathrm{B} x}$ is the number of persons below either of the two cut-off points in age interval $x$, and $Y_{x}$ is the YLL in age interval $x$. 
Table 1

Basic demographic characteristics of the MEPS sample

\begin{tabular}{|c|c|c|c|c|c|}
\hline Variable & Total & $<T$ & $\geqslant T$ & $<80 \%$ & $\geqslant 80 \%$ \\
\hline \multicolumn{6}{|l|}{ Age distribution } \\
\hline $0-17$ & 26.3 & 38.3 & 24.7 & 30.4 & 19.8 \\
\hline $18-44$ & 39.3 & 35.5 & 39.8 & 38.9 & 40.0 \\
\hline $45-64$ & 22.4 & 15.1 & 23.3 & 16.7 & 31.4 \\
\hline $65+$ & 12.0 & 11.0 & 12.2 & 14.0 & 8.89 \\
\hline \multicolumn{6}{|l|}{ Race and ethnicity } \\
\hline White, non-Hispanic & 71.2 & 49.3 & 74.0 & 63.2 & 84.0 \\
\hline Black, non-Hispanic & 12.6 & 23.7 & 11.1 & 16.1 & 6.89 \\
\hline Asian, non-Hispanic & 3.39 & 2.64 & 3.49 & 3.30 & 3.55 \\
\hline Native American, non-hispanic & 0.64 & 1.85 & 0.49 & 0.88 & 0.27 \\
\hline Hispanics & 12.2 & 22.5 & 10.9 & 16.5 & 5.25 \\
\hline \multicolumn{6}{|l|}{ Sex } \\
\hline Male & 48.8 & 43.2 & 49.5 & 47.3 & 51.3 \\
\hline Female & 51.2 & 56.8 & 50.5 & 52.7 & 48.7 \\
\hline \multicolumn{6}{|l|}{ Marital status } \\
\hline Married & 53.6 & 32.0 & 56.0 & 46.5 & 63.7 \\
\hline Widowed & 6.94 & 11.9 & 6.39 & 9.53 & 3.27 \\
\hline Divorced & 10.6 & 14.0 & 10.2 & 11.9 & 8.72 \\
\hline Separated & 1.59 & 3.98 & 1.33 & 2.24 & 0.67 \\
\hline Never married & 27.3 & 38.1 & 26.1 & 29.9 & 23.6 \\
\hline \multicolumn{6}{|c|}{ Metropolitan statistical area (MSA) } \\
\hline Non-MSA & 18.5 & 20.4 & 18.3 & 21.2 & 14.2 \\
\hline MSA & 81.5 & 79.6 & 81.7 & 78.8 & 85.8 \\
\hline \multicolumn{6}{|l|}{ Insurance } \\
\hline Any private & 72.6 & 26.9 & 78.6 & 60.8 & 91.6 \\
\hline Public only & 15.7 & 51.6 & 11.0 & 23.4 & 3.35 \\
\hline Uninsured & 11.7 & 21.5 & 10.4 & 15.8 & 5.02 \\
\hline \multicolumn{6}{|l|}{ Self-reported health $(18+$ only $)$} \\
\hline Fair or poor & 15.0 & 32.4 & 13.1 & 20.0 & 7.85 \\
\hline
\end{tabular}

Numbers are in percentages within the column (e.g., $48.8 \%$ male $+52.2 \%$ female $=100 \%$. $T=$ poverty threshold, $\geqslant 80 \%$ reflects the bottom $80 \%$ of households with respect to income, and $\geqslant 80 \%$ reflects the top $20 \%$ of households with respect to income ( $\geqslant \$ 80,040$ in 2000).

\section{Results}

Table 1 shows the demographic profile of persons by income group in the MEPS sample. Adults living in poverty, and with $<80 \%$ in household earnings are more likely to be young, female, Hispanic, AfricanAmerican or American-Indian, and more likely to report poor or average health than persons living above the two cut-off points.

Table 2 shows annual age-specific income related and poverty-associated deaths alongside YLL and HALYs. In the year 2000, there were 361,253 additional deaths and almost 11 million years of life lost to adults in the bottom $80 \%$ of earnings relative to those in the top income category. There were also 17.4 million incomerelated HALY among adults. In our analysis of HALYs based on an extrapolation of HRQL to birth, this number increases to 20.3 million HALYs (data not shown). Poverty-associated values totaled 1.9 million additional YLL and 3.2 million additional HALYs among adults relative to those living above the poverty threshold. The use of a global HR (rather than agespecific HRs) produces 861,000 income related deaths and 93000 poverty-related deaths.

Table 3 shows the lifelong effects of living above or below the relevant cut-off points for the average individual. Life expectancy was 59.7 for the average 18-year-old, 54.9 for poor 18 -year-olds, 60.5 for 18 -yearolds living above the poverty threshold, 58.8 for persons in the bottom $80 \%$ of household income, and 63.2 for those in the top $20 \%$ of household income. This amounts to a 5.6-year difference in adult life expectancy 
Table 2

Income related (top $20 \%$ relative to bottom $80 \%$ ) and poverty associated (below the poverty threshold relative to those above it) hazard ratio (HR), deaths, years of life lost, and health adjusted life years (HALYs)

\begin{tabular}{|c|c|c|c|c|}
\hline & $\mathrm{HR}$ & Deaths & YLLs & HALYs \\
\hline \multicolumn{5}{|c|}{$<$ Poverty threshold } \\
\hline $18-24$ & $1.56(1.05,2.31)$ & 1527 & 104,348 & 311,447 \\
\hline $25-44$ & $2.51(2.11,3.00)$ & 17,013 & 792,741 & $1,326,379$ \\
\hline $45-64$ & $2.08(1.82,2.39)$ & 32,785 & 921,410 & $1,231,009$ \\
\hline $65-74$ & $1.33(1.15,1.53)$ & 12,589 & 202,280 & 304,959 \\
\hline$>75$ & $0.94(0.85,1.04)$ & -9605 & $-107,629$ & $-23,228$ \\
\hline Total & $1.34(1.25,1.43)$ & 54,308 & $1,913,148$ & $3,150,566$ \\
\hline \multicolumn{5}{|c|}{$<80 \%$ Income } \\
\hline $18-24$ & $1.41(0.88,2.27)$ & 5094 & 361,583 & $1,149,863$ \\
\hline $25-44$ & $2.38(1.96,2.94)$ & 70,283 & $3,460,112$ & $6,376,129$ \\
\hline $45-64$ & $1.96(1.72,2.22)$ & 171,824 & $5,188,837$ & $7,077,095$ \\
\hline $65-74$ & $1.45(1.22,1.69)$ & 114,052 & $1,942,506$ & $2,328,160$ \\
\hline$>75$ & $1.00(0.88,1.22)$ & 0 & 0 & 493,200 \\
\hline Total & $1.59(1.47,1.69)$ & 361,253 & $10,953,038$ & $17,424,446$ \\
\hline
\end{tabular}

Table 3

Income-related changes in life expectancy and quality-adjusted life expectancy in the US, 2000

\begin{tabular}{|c|c|c|c|c|c|}
\hline & US mean & $<T$ & $\geqslant T$ & $<80 \%$ & $\geqslant 80 \%$ \\
\hline \multicolumn{6}{|c|}{ Life expectancy (years) } \\
\hline Age 18 & 59.7 & 54.9 & 60.5 & 58.8 & 63.2 \\
\hline $\mathrm{All}^{\mathrm{a}}$ & 76.8 & 71.7 & 77.8 & 76.0 & 80.3 \\
\hline \multicolumn{6}{|c|}{ Quality-adjusted life expectancy $(H A L Y S)$} \\
\hline Age 18 & 51.1 & 43.7 & 52.2 & 49.8 & 55.6 \\
\hline $\mathrm{All}^{\mathrm{a}}$ & 67.2 & 59.1 & 68.6 & 66.0 & 72.3 \\
\hline
\end{tabular}

$T=$ poverty threshold, $<80 \%$ reflects the bottom $80 \%$ of households with respect to income, and $\geqslant 80 \%$ reflects the top $20 \%$ of households with respect to income ( $\geqslant \$ 80,040$ in 2000).

${ }^{\mathrm{a}}$ Estimates based on HRQL scores and hazard ratios derived by regression.

between those above and below the poverty threshold, and a 4.3-year difference for those above and below the $80 \%$ income line. (Differences between numbers in the table and text are due to rounding.)

The average 18-year-old in poverty lived 8.5 HALYS less than the average 18-year-old above the poverty threshold in 2000, and the average adult in a household below the $80 \%$ earnings threshold lived 5.8 fewer HALYs relative to adults in the top $20 \%$ of households.

Based on HRQL scores extrapolated to birth, the life expectancy at birth for persons living below the poverty threshold was roughly 71.7 years compared with 77.8 years for those living above the poverty threshold in 2000. Life expectancy for the $<80 \%$ group was 76 years, and was 80.3 years for the $\geqslant 80 \%$ group. The mean life expectancy for all US households was 76.8 years. Persons living below the poverty threshold live 6.1 years and 9.6 HALYs less than those above the poverty threshold. Those in the top $\geqslant 20 \%$ of household income live an average of approximately 4.3 years and 6.4 HALYs longer from birth than those with family incomes in the bottom $80 \%$ of households.

\section{Discussion}

In the US, poor adults suffered 1.9 million YLL, lost 3.2 million HALYs, and lived 5.6 fewer years relative to adults living above the poverty threshold. These numbers grow substantially when estimates for children are included. However, even if the morbidity and mortality experience of the poorest persons were erased, it would account for a relatively small proportion of the income-associated burden of disease in the US.

Persons in the top $20 \%$ of households by earnings enjoy substantially longer lives and experience considerably less morbidity than the bottom $80 \%$. They live 4.3 years and 6.4 HALYs longer than the remainder of the 
population. This amounts to an annual difference of nearly 11 million years of prematurely lost life or 17.4 million HALYs.

There is a good deal of debate surrounding the source of morbidity and mortality differences between the richest Americans and all others (Deaton, 2002; Fuchs, 2004). While concrete links can be drawn between poverty and mortality, mechanisms for the health gradient among wealthier persons are thought by some to be driven to a greater extent by psychobiological factors than by resource-related factors like access to health care or healthy foods (Cohen, Doyle, \& Skoner, 1999; Markowe et al., 1985; McEwen, 1998; Owen , Poulton, Hay, Mohamed-Ali, \& Steptoe, 2003; Steptoe et al., 2002). Psychosocial factors include social support networks, job control, and, possibly, perceived social status.

Others argue that the higher mortality among middleincome persons relative to those with higher incomes is simply an extension of the cumulative effects seen among lower income persons (Lynch et al., 2004). For instance, wealthier persons are likely to have greater access to effective, but expensive medical interventions than those with less income. Consistent with this materialistic explanation of the income-mortality relationship, multi-level studies by Fiscella and Franks among others have indicated that income is a more potent predictor of mortality than is income inequality (reflecting more psychological or social effects) (Fiscella \& Franks, 1997a,b). Regardless of the mechanism, the policy implications are similar; proposed and existing solutions address improvements in earned income, health insurance coverage, and educational attainment (CDC, 2002; Haveman, 1995; Johnson, 2001; Kehrer \& Wolin, 1979; Smeeding et al., 2000).

Policies aimed at assisting the poor may be less contentious than policies such as universal health coverage, which is mostly directed at the middle class. Social programs aimed at reducing poverty have shown some success. For instance, there is evidence that poverty can be reduced through tax credit and school retention programs, among many others (CDC, 2002; Haveman, 1995; Johnson, 2001; Smeeding et al., 2000).

The extent to which these interventions reduce the burden of disease we have tabulated here hinges on the extent to which the health effects of poverty are reversible (among those who are already poor) or preventable (among those who might otherwise become poor). The evidence supporting a causal association between income and illness includes randomized controlled trials and natural experiments. In the Gary Income Maintenance Experiment, high risk women that were randomized to an experimental alternative negative income tax group had much higher birth weight neonates than control mothers (Kehrer \& Wolin, 1979). Sacerdote has found that Korean children that were essentially randomly assigned to adoptive families have better health status and are more likely to go to college if they were assigned to high SES parents (Sacerdote, 2004). A subset of patients randomized to receive health insurance with no copayments had lower mortality than those assigned to receive insurance with a copayment (Brook et al., 1983). Finally, those randomized to receive housing vouchers for private dwellings showed improvements in health status (Kling, Liebman, Katz, \& Sanbonmatsu, 2004; Kling, Ludwig, \& Katz, 2004).

While environmental factors such as poor housing stock and lack of access to healthy foods might be difficult to eliminate via regulatory policy, the evidence for larger scale policy interventions are more promising. On a local level, successful poverty reduction initiatives have demonstrated health benefits that appear to go beyond the benefits expected from traditional clinical or public health interventions (Geiger, 2002).

Other income maintenance programs are important as well. For instance, in addition to the impact of lower income on health, poor health is responsible for some loss of income (Smith, 1999). Job loss affects total household income in part because disability insurance is often either lacking or inadequate to sustain a family's income. This is especially true in single income households because there is no second adult available to compensate for the hours of work lost.

The relative magnitude of each pathway (i.e., lower incomes leading to disease versus illness leading to lower incomes) is important when considering which redistributive policies should be prioritized. Prospective, incidence-based data show that reverse causality (illness causing lower income) plays a small role in the 3-4 fold higher risk of morbidity and mortality (Haan, Kaplan, \& Camacho, 1987; Lynch, Kaplan, \& Shema, 1997; Smith et al., 1990).

We felt that age was the only appropriate covariate to include in this analysis because other variables are in the poverty-health pathway. For instance, low-income persons are also more likely to have dangerous low paying jobs. Controlling for occupation would thus erase a large proportion of this effect. However, some covariates exert both positive and negative effects outside of the poverty pathway. For instance, immigrants and native-born Hispanics are both more likely to be poor and more likely to be healthy than native-born non-Hispanic whites (Muennig \& Fahs, 2002; Sorlie, Backlund, \& Keller, 1995). Presumably, the health of these groups has nothing to do with their low income. African-Americans, on the other hand, are both more likely to have lower incomes and to be sick. Most of this effect is due to lower socio-economic status (Williams, 1999). However, there is evidence that discrimination may play a role that is independent of socio-economic status (Williams, 1999). 
There is a literature examining the health effects of upward mobility, downward mobility, and sustained hardship. For instance Lynch et al. (1997) examined prospective data on healthy persons over a 25-year period. Relative to those without economic hardship measured over 3 time intervals, those with sustained economic hardship have a 5.9-fold increased risk of difficulties performing basic physical tasks while those with one or two episodes of hardship have a risk of 1.6 and 3.5, respectively. Our data measure income at just one point in time and follow subjects over a short interval for mortality. It is difficult to gauge the extent to which the cumulative versus transient effects of deprivation affect our results.

Our study improved upon previous US burden of disease analyses by using large, nationally representative datasets, calculating age-specific HRs, and by incorporating a HALY compatible summary measure of morbidity. The incorporation of a preference-based HALY compatible measure (the EQ-5D Index included in the 2000 MEPS) allows for the quantification of overall morbidity alongside mortality (Coons et al., 2000; Gold et al., 1996).

Some noteworthy limitations exist. First, we calculated age-specific risk ratios for mortality using mortality data from 1990-1992 through the end of 1995. Although mortality rates change over time, relative risk by income appears to remain more stable, though differences may have increased recently (thus producing an underestimate of the burden of disease) (Blane, Smith, \& Bartley, 1990; Kunst et al., 2004). Second, because of differences in the conceptualization of health and the method by which health states are valued, HRQL measures vary in their ability to capture morbidity. The EQ-5D Index displays reasonable reliability and validity when compared to other healthrelated quality of life measures, however, the measure has known ceiling effects stemming from the limited number of severity levels (Johnson \& Coons, 1998). Thus, this tool may produce an underestimate of all cause morbidity. Third, the data sources we used to calculate annual data (total deaths, the YLL, and the HALY) only include the non-institutionalized US civilian population. Those in institutions (primarily nursing homes and prisons) are poorer and sicker on average than those not in institutions.

Total deaths are typically calculated using adjusted hazard ratios. An adjusted hazard ratio will correctly estimate deaths provided the total number of deaths is relatively consistent in each age interval or the ratio does not change with age. Since most deaths occur late in life, and the risk of death due to most factors diminishes with age (possibly due to the survivor effect), traditional methods tend to overestimate deaths. Using this traditional approach, over a third (861 000) of all deaths are attributable to income differences. However, when age-specific ratios are used, this number drops to 361000 . Of the 2.4 million registered deaths in the year $2000,361000(15 \%)$ were income related and 54000 $(2.3 \%)$ were poverty associated. We await improved age-group adjusted estimates of other causes of death; with those downwardly revised estimates, however, we anticipate income-associated deaths will exceed those attributable to tobacco and obesity (CDC, 2002).

To our knowledge, this is the first examination of the income related burden of disease, though others have looked at the impact of socioeconomic status on depression and obesity (Goodman, Slap, \& Huang, 2003). It is also the first study to incorporate nationally representative morbidity and mortality data in burden of disease estimation. Further study is needed to examine the extent to which this large-scale loss of life might be ameliorated through interventions (educational and fiscal), such as those currently underway in Europe and Australia (Acheson, 2002).

\section{References}

Acheson, D. (2002). Independent inquiry into inequalities in health report. London: The Stationary Office (p. 164).

AHRQ (1996). Medical Expenditure Panel Survey.

Anderson, R. (1999). Method for constructing complete annual life tables. National Center for Health Statistics. Vital Health Stat, 2(129), 1-35.

Blane, D., Smith, G. D., \& Bartley, M. (1990). Social class differences in years of potential life lost: Size, trends, and principal causes. British Medical Journal, 301(6749), 429-432.

Brook, R. H., Ware, J. E., Jr., Rogers, W. H., Keeler, E. B., Davies, A. R., Donald, C. A., Goldberg, G. A., Lohr, K. N., Masthay, P. C., \& Newhouse, J. P. (1983). Does free care improve adults' health? Results from a randomized controlled trial. New England Journal of Medicine, 309(23), 1426-1434.

CDC. (2002). Annual smoking-attributable mortality, years of potential life lost, and economic costs-United States, 1995-1999. MMWR Morb Mortal Weekly Report, 51(14), 300-303.

Cohen, S., Doyle, W. J., \& Skoner, D. P. (1999). Psychological stress, cytokine production, and severity of upper respiratory illness. Psychosomatic Medicine, 61(2), 175-180.

Cohen, S. B. (2003). Design strategies and innovations in the medical expenditure panel survey. Medical Care, 41, $1115-1121$.

Coons, S. J., Rao, S., Keininger, D. L., \& Hays, R. D. (2000). A comparative review of generic quality-of-life instruments. Pharmacoeconomics, 17(1), 13-35.

Deaton, A. (2002). Policy implications of the gradient of health and wealth. An economist asks, would redistributing income improve population health? Health Affairs (Millwood), 21(2), 13-30.

Fiscella, K., \& Franks, P. (1997a). Individual income, income inequality, health, and mortality: What are the relationships? Health Services Research, 35, 307-318. 
Fiscella, K., \& Franks, P. (1997b). Does psychological distress contribute to racial or socioeconomic disparities in mortality? Social Science Medicine, 45, 1805-1809.

Flegal, K. M., Williamson, D. F., Pamuk, E. R., \& Rosenberg, H. M. (2004). Estimating deaths attributable to obesity in the United States. American Journal of Public Health, 94(9), 1486-1489.

Fuchs, V. (2004). Reflections on the socio-economic correlates of health. Journal of Health Economics, 23, 653-661.

Geiger, H. J. (2002). Community-oriented primary care: A path to community development. American Journal of Public Health, 92(11), 1713-1716.

Gold, M., Siegel, J., Russell, L., \& Weinstein, M. (1996). Costeffectiveness in health and medicine. New York: Oxford University Press.

Goodman, E., Slap, G. B., \& Huang, B. (2003). The public health impact of socioeconomic status on adolescent depression and obesity. American Journal of Public Health, 93(11), 1844-1850.

Haan, M., Kaplan, G. A., \& Camacho, T. (1987). Poverty and health. Prospective evidence from the Alameda County Study. American Journal of Epidemiology, 125(6), 989-998.

Haveman, R. (1995). Reducing poverty while increasing employment: A primer on alternative stategies, and a blueprint. The OECD Jobs Study Working Paper Series. Paris: Organization for Economic Cooperation and Development.

Johnson, J. A., \& Coons, S. J. (1998). Comparison of the EQ5D and SF-12 in an adult US sample. Quality of Life Research, 7, 155-166.

Johnson, N. (2001). A Hand Up: How State Earned Income Tax Credits Help Working Families Escape Poverty in 2001. Washington: Center on Budget and Policy Priorities, 2001. Available online at: http://www.cbpp.org/3-3-03sfp.htm $<$ http://www.cbpp.org/3-3-03sfp.htm > .

Kehrer, B. H., \& Wolin, C. M. (1979). Impact of income maintenance on low birth weight: Evidence from the Gary Experiment. Journal of Human Resources, 14(4), 434-462.

Kling, J., Liebman, J., Katz, L., \& Sanbonmatsu, L. (2004). Moving to opportunity and tranquility: Neighborhood effects on adult economic self-sufficiency and health from a randomized housing voucher experiment. NBER: NBER.

Kling, J., Ludwig, J., \& Katz, L. (2004). Neighborhood effects on crime for female and male youth: Evidence from a randomized housing voucher experiment. Quarterly Journal of Economics.

Kunst, A. E., Bos, V., Lahelma, E., Bartley, M., Lissau, I., Regidor, E., Mielck, A., Cardano, M., Dalstra, J. A., Geurts, J. J., Helmert, U., Lennartsson, C., Ramm, J., Spadea, T., Stronegger, W. J., \& Mackenbach, J. P. (2004). Trends in socioeconomic inequalities in self-assessed health in 10 European countries. International Journal of Epidemiology.

Lantz, P. M., House, J. S., Lepkowski, J. M., Williams, D. R., Mero, R. P., \& Chen, J. (1998). Socioeconomic factors, health behaviors, and mortality: Results from a nationally representative prospective study of US adults. JAMA, 279(21), 1703-1708.

Lynch, J., Davey Smith, G., Harper, S., Hillemeier, M., Ross, N., Kaplan, G. A., \& Wolfson, M. (2004). Is income inequality a determinant of population health? Part 1. A systematic review. Milbank Quarterly, 82, 5-99.

Lynch, J. W., Kaplan, G. A., \& Shema, S. J. (1997). Cumulative impact of sustained economic hardship on physical, cognitive, psychological, and social functioning. New England Journal of Medicine, 337(26), 1889-1895.

Markowe, H. L., Marmot, M. G., Shipley, M. J., Bulpitt, C. J., Meade, T. W., Stirling, Y., Vickers, M. V., \& Semmence, A. (1985). Fibrinogen: A possible link between social class and coronary heart disease. British Medical Journal (Clinical Research Edition), 291(6505), 1312-1314.

McEwen, B. S. (1998). Protective and damaging effects of stress mediators. New England Journal of Medicine, 338(3), 171-179.

McGinnis, J. M., \& Foege, W. H. (1993). Actual causes of death in the United States. JAMA, 270(18), 2207-2212.

Michaud, C. E., Murray, C. J. L., \& Bloom, J. R. (2001). Burden of disease-implications for future research. JAMA, 285, 535-539.

Minino, A., Arias, E., KD, K., Murphy, S., \& Smith, B. (2002). Deaths: Final data for 2000. National Vital Statistics Reports, 50(15).

Mokdad, A. H., Marks, J. S., Stroup, D. F., \& Gerberding, J. L. (2004). Actual causes of death in the United States, 2000. JAMA, 291(10), 1238-1245.

Muennig, P. (2002). Designing and conducting cost-effectiveness analyses in medicine and health care. San Francisco: JosseyBass.

Muennig, P., \& Fahs, M. C. (2002). Health status and hospital utilization of recent immigrants to New York City. Preventine Medicine, 35(3), 225-231.

NCHS (1993). National Health Interview Survey.

NCHS (1995). National Death Index.

Owen, N., Poulton, T., Hay, F. C., Mohamed-Ali, V., \& Steptoe, A. (2003). Socioeconomic status, C-reactive protein, immune factors, and responses to acute mental stress. Brain Behaviours and Immunities, 17(4), 286-295.

Rabin, R., \& de Charro, F. (2001). EQ-5D: A measure of health status from the EuroQol Group. Annals Medicine, 33, 337-343.

Rogot, E. (1992). A mortality study of 1.3 million persons by demographic, social, and economic factors: 1979-85 followup. Bethesda, MD: National Institutes of Health.

Sacerdote, B. (2004). What happens when we randomly assign children to families? NBER: NBER.

Simonoff, J. (1996). Smoothing methods in statistics. New York: Springer.

Smeeding, T., Ross, K., \& O'Connor, M. (2000). The EITC: Expectation, knowledge, use, and economic and social mobility. National Tax Journal.

Smith, G. D., Shipley, M. J., \& Rose, G. (1990). Magnitude and causes of socioeconomic differentials in mortality: Further evidence from the Whitehall Study. Journal of Epidemiology and Community Health, 44(4), 265-270.

Smith, J. P. (1999). Healthy bodies and thick wallets: The dual relation between socio-economic status and health. Journal of Economic Perspectives, 13, 145-166.

Sorlie, P. D., Backlund, E., \& Keller, J. B. (1995). US mortality by economic, demographic, and social characteristics: The national longitudinal mortality study. American Journal of Public Health, 85(7), 949-956. 
Steptoe, A., Feldman, P. J., Kunz, S., Owen, N., Willemsen, G., \& Marmot, M. (2002). Stress responsivity and socioeconomic status: A mechanism for increased cardiovascular disease risk? European Heart Journal, 23(22), 1757-1763.

Stevenson, T. (1923). The social distribution of mortality from different causes in England and Wales, 1910-12. Biometrika, $15,382-400$.
Williams, D. R. (1999). Race, socioeconomic status, and health. The added effects of racism and discrimination. Annals of the New York Academy of Sciences, 896, 173-188.

Wolfson, M., Rowe, G., Gentleman, J. F., \& Tomiak, M. (1993). Career earnings and death: A longitudinal analysis of older Canadian men. Journal of Gerontology, 48(4), S167-S179. 